\title{
Spatial clustering of people with memories and responses six years after an earthquake in Cauquenes, Chile
}

\author{
Marcelo Leiva-Bianchi, ${ }^{1}$ Carlos Mena, ${ }^{2}$ Yony Ormazábal, ${ }^{2}$ Carlos Serrano ${ }^{1}$ \\ ${ }^{1}$ Laboratory of Methodology and Data Analysis for Behavioral and Neurosciences, Faculty of Psychology, \\ University of Talca; ${ }^{2}$ Geomatics Center, Faculty of Forest Sciences, University of Talca, Chile
}

\begin{abstract}
The occurrence of earthquakes can cause psychiatric problems expressed as unpleasant and uncontrollable memories of the event termed post-traumatic stress disorder (PTSD). Mapping the location of people and identifying their exposure and reactions to an earthquake can be extremely valuable from a public, mental health point of view. The main objective of this study was to examine people with respect to PTSD and healthy post-traumatic growth (PTG) after an earthquake searching for expression of geographic clustering that could be useful for a better understanding of mental health conditions. Geographic information systems analyses were performed to detect global and local geographic clustering. Investigating 171 randomly selected adults from Cauquenes, Chile, we demonstrated spatially clustered variables related to PTSD and PTG in Cauquenes six years after an earthquake. Urban and peri-urban areas had clear differences (hotspots/coldspots). The spatial identifications found should facilitate exploring the impact of mental health programmes in communities exposed to disasters like earthquakes, thereby improving their quality of life as well as reducing overall costs.
\end{abstract} Correspondence: Yony Ormazábal, Geomatics Center, Faculty of Forest
Sciences, University of Talca, Chile.

E-mail: yormazabal@utalca.cl

Key words: Post-traumatic stress disorder; Post-traumatic growth; Earthquake; Geographic Information Systems; Getis-Ord Gi*; Chile.

Conflict of interest: the authors declare no potential conflict of interest.

Funding: this work was supported by the FONDECYT-Chile 1160301 and CONICYT PhD in Human Sciences (Doctorado en Ciencias Humanas) 21181845.

Received for publication: 17 May 2019.

Revision received: 21 August 2019.

Accepted for publication: 10 October 2019.

${ }^{\circ}$ Copyright: the Author(s), 2019

Licensee PAGEPress, Italy

Geospatial Health 2019; 14:789

doi:10.4081/gh.2019.789

This article is distributed under the terms of the Creative Commons Attribution Noncommercial License (CC BY-NC 4.0) which permits any noncommercial use, distribution, and reproduction in any medium, provided the original author(s) and source are credited.

\section{Introduction}

Mental health after earthquakes has generally been measured in terms of disruptive responses in those exposed, mainly post-traumatic stress disorder (PTSD) expressed as unpleasant and uncontrollable memories of the event, a tendency to avoiding stimuli associated with the event, mood swings or hyper activation (American Psychiatric Association, 2013). Shortly after an earthquake, it is expected that $29 \%$ of people show PTSD (Leiva-Bianchi, 2011; Dai et al., 2016), a percentage that decreases only slowly and can persist for many years (Smid et al., 2009), particularly in the absence of effective treatment (Bradley et al., 2005; Ehring et al., 2014; LeivaBianchi et al., 2018a). Likewise, there are also studies of healthy responses after earthquakes such as post-traumatic growth (PTG) allowing people to adapt positively (Xu and Liao, 2011; Andrades et al., 2018). PTG generally includes positive changes with regard to self-image and self-confidence as well as improvement of interpersonal relationships, spirituality and view of life (Tedeschi et al., 2018). Although it is known that PTSD increases with the degree of physical exposure to an earthquake (e.g., distance to the epicentre, damage to housing (Leiva, 2010; Abeldaño et al., 2013), similar studies were not found regarding healthy responses such as PTG. Since destruction within urban centres is not homogeneous, it can be expected that the occurrence and degree of PTSD and PTG follow suit. This is particularly common in Chile, where earthquakeresistant building construction was introduced after the Valdivia earthquake in 1960; still the largest recorded. However, this earthquake was not so destructive in the cities at the centre of the country, where the old adobe homes maintained their structural integrity until the earthquake of February 27, 2010 (F-27), the ninth most intense in the world so far. Cauquenes then suffered loss of numerous homes located in its historical centre with old downtown neighbourhoods, whose adobe buildings did not resist F-27. This indicates that both the PTSD and the PTG could have a different distribution according to the geographic location of the dwellings. In general, three theories explain the different distributions of disruptive and healthy responses.

\section{First theory}

The resource-conservation model, which holds that when a disaster occurs, resources available to the community decrease, which causes the community to try to conserve the pre-disaster situation (Hobfoll, 2014). This produces a stress situation, which is greater in communities with lower income and higher unemployment. Post-disaster assistance helps protect people, especially during the first months after the emergency, but once the supportive activities cease, the final level of stress may be even greater (Hobfoll, 2014). 


\section{Second theory}

The support-deterioration deterrence model (Kaniasty and Norris, 2009), which is not entirely different, but stresses the fact that people might act disruptively, e.g., PTSD, if support is not maintained over time. Although the model agrees that initial help is useful, the very presence of support produces a paradoxical negative effect on mental health by not being continuous. This leads to a situation where survivors continue to be exposed to stress after a disaster, since their social support decreases and that, in turn, increases the risk of psychological disorders.

\section{Third theory}

The psychosocial impact model (Leiva-Bianchi et al., 2018b), which maintains that disruptive responses are based on the level of exposure to the disaster, which in the case of earthquakes is related to the degree of damage to housing in various sectors of the city (e.g., neighbourhood, village). According to the exposure level and the response given, this model classifies people according to four types of impact: i) traumatic, i.e. exposed people who respond in a disruptive manner (e.g., PTSD); ii) resilient, i.e. exposed people who respond in a healthy way (e.g., PTG); iii) bystanders, i.e. unhurt people who respond healthily; and iv) paradoxical, i.e. unhurt people who respond disruptively.

Since geographic clustering can be of interest in relation to disasters, such as earthquakes, it should be of interest to apply statistical approaches capable of revealing such developments. Usually, global statistics provide an autocorrelation parameter that reveals the spatial pattern whereas local statistics identify the specific locations of clusters, whether they are hotspots or coldspots (Singh et al., 2016). For example, Global Moran's $I$ can be applied to identify spatial association in a large group of values of spatially dispersed individuals (Fotheringham and Brunsdon, 1999). Moreover, local indicators of spatial association (LISA) statistics, like Getis-Ord, can be applied to detect clusters where there is a local spatial association between a value registered for one individual and his or her neighbours within a specified distance (Roger et al., 2012). Mena et al. (2017) applied this methodology to detect geographic clustering of elderly people with above-norm anthropometric measurements and blood chemistry. In the mental health field, Ruiz-Grosso et al. (2016) studied the spatial distribution of individuals with symptoms of depression in a peri-urban area in Lima, Peru, applying geographical information systems (GIS) that enables the identification of spatial patterns of cases with depressive symptoms, contributing to an understanding of underlying mechanisms supporting the identification of high- and low-risk populations. The objective of this study was to examine the PTSD and PTG of people after an earthquake, searching for the presence of geographic clustering that could be useful for a better understanding of mental health conditions. Although the scientific literature has reported studies on geo-spatial variables and mental health after disasters, e.g., a hurricane (Lowe et al., 2016), our aim was to link PTSD and PTG with geo-spatial variables, which has not been done previously.

\section{Materials and Methods}

\section{Study site}

The study was conducted in the urban centre of Cauquenes, Maule Region, Chile (Figure 1). The city is made up of the follow-

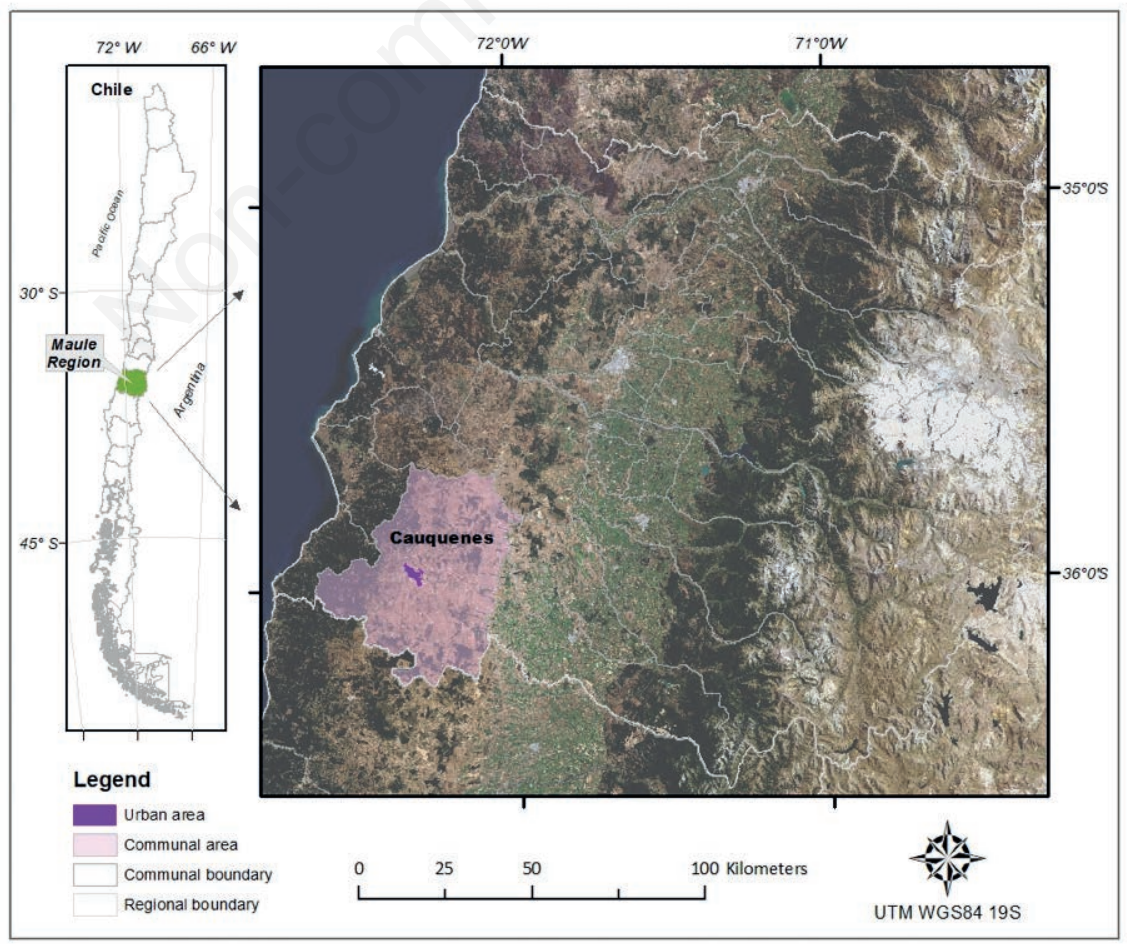

Figure 1. Localisation of the study area. 
ing sectors and villages: the city centre (downtown) which consists of commercial activities in combination with the oldest residential sectors; in the Northwest, the Los Poetas and Bombero Venegas villages, which are working-class residential sectors that receive state contributions to improve its urban environment; in the Northeast, the Fernández Village, which is a residential sector with high poverty rates and less urban development; and in the South, the Estación Village, which is a residential sector characterised by people with higher income and where there is greater urban development.

\section{Participants}

A sample of dwellings from different city blocks was randomly obtained from the city considering a total of 7,321 dwellings distributed between 306 blocks. The participation of a key informant was requested from each dwelling, that is a person over 18 who was the head of the household. Instituting a 5\% confidence level and a power of $80 \%$, a total of $171(65.5 \%$ women $)$ inhabitants of Cauquenes were sampled for the study, considering one inhabitant per dwelling (Table 1). Thus, a two-stage cluster sampling was made from blocks and dwellings in the urban area of Cauquenes. The age group with the highest frequency was those over 65 years of age $(33.3 \%)$.

\section{Assessment of severity of symptoms}

After voluntarily agreeing to participate, a properly trained interviewer applied the Short Post-Traumatic Stress Disorder Rating Interview (SPRINT-E) and Post-traumatic Growth Inventory (PTGI) scales. SPRINT-E is composed of 12 measures of PTSD expected after a disaster (e.g., adjustment to daily life, alcohol use, drug use, suicidal inclination, etc. Each measure is scored on a scale ranging from 0 up to 4 , which means a possible maximum of 48 points. A total of 9 points or more, including 3 measures with at least 3 points, is considered a case of PTSD (Norris et al., 2008; Leiva-Bianchi and Gallardo, 2013). Specifically, the first 3 measures are added to obtain the PTSD symptoms variable and the sum of the others allows the PTSD reactions to be obtained. The PTGI scale, on the other hand, is composed of 21 measures that gauge the mental growth and personal development of those who have experienced a potentially traumatic event such as a disaster (relating to others; new possibilities; personal strength; spiritual change; and appreciation of life). Each measure is assessed using a scale from 0 up to 5, which means a possible maximum of 105 points. Depending on the number of points from the level can vary from little change (0 to 50 points); over moderate change (51-74 points) to big change ( $>75$ points) when used (Tedeschi and Calhoun, 1996; Leiva-Bianchi and Araneda, 2015).

\section{The mental health geodata base}

A geo-referenced database of Cauquenes was built in ArcGIS software v. 10 (ESRI, Redlands, CA, USA). This database contains all relevant geo-information (roads, urban blocks and green areas obtained from the Military Geographic Institute of Chile cartography and satellite images from the Worldview satellites (https://www.maxar.com/) for supporting the georeferencing of post-traumatic data acquired by surveying. All information collected was stored and organised as independent information layers conforming a base map where every single individual was geolocated (i.e. the home address recorded during the psychological evaluation). Thus, a GIS coverage was created using georeferenced points as representative element for individuals and all the psychological evaluation data linked as a thematic table (Mena et al., 2016). This GIS coverage was the main input data for the calculation of post-traumatic indices and the spatial autocorrelation analyses.

The Moran's $I$ statistic values, which can range between -1 to +1 , was calculated according to Zhao et al. (2013) and Chen et al. (2015). A value near +1 indicates that values tend to cluster, while a value near -1 indicates that higher and lower measurement values are heterogeneously distributed in the analysed area. This approach was used to analyse the correlation among post-traumatic indices of neighbouring individuals in order to detect whether the spatial distribution was clustered, dispersed or random. The threshold distance used in the analyses for the searching ratio was $700 \mathrm{~m}$, a distance that represent a mean size of a village sector of the city. Importantly, Moran's I values recorded for the psychological indices of an individual at one location do not depend on the neighbourhood conditions.

\section{Local cluster detection of post-traumatic effects}

The Gi* local statistic (Ord and Getis, 1995) was used to analyse the spatial correlation among post-traumatic indices of neighbouring individuals in order to detect statistically significant spatial clusters of high (hotspots) or low value (coldspots). The analyses were completed for those psychological evaluation variables that showed a clustered condition according to Moran's $I$. In this case, the $\mathrm{Gi}^{*}$ statistic itself is a $z$-score, so no further calculations were needed. Thus, the $z$-score and P-value were used to identify where individuals with either high or low values were clustered spatially. A hotspot or coldspot was identified when an individual had a high (or low) value surrounded by other individuals with similar (high or low) values. Therefore, individuals with a positive $z$-score correspond to a spatial clustering of high values and individuals with a negative $z$-score correspond to a one with low values. The higher (or lower) the $z$-score is, the more intense the clustering, while the $z$-scores close to zero do not indicate any apparent clustering (Getis and Aldstadt, 2004).

\section{Results}

In total, the prevalence of PTSD associated with the impact of the F-27 earthquake was $24.6 \%$ (76.2\% women), while the percentage of people with high PTG was $55 \%$ (69.1\% women).

The results of the Moran's $I$ analyses is shown in Table 2, where it can be seen that seven of the variables under analysis

Table 1. The study population.

\begin{tabular}{lcc} 
Variable & N & $\%$ \\
Women & 112 & 65.5 \\
Men & 59 & 34.5 \\
\hline Age $>65$ & 57 & 33.3 \\
High school completed & 52 & 30.4 \\
\hline Living alone & 20 & 11.7 \\
Income level: 281-563 USD & 78 & 45.6 \\
\hline
\end{tabular}

USD, United States dollars. 
(total PTG; spiritual change, change in interests or activities with some people undertaking new vital projects; appreciation of life; total PTSD; and symptoms/reactions) were spatially clustered. Table 3 shows the mean values that came into view when these clustered variables were subjected to local $\mathrm{Gi}^{*}$ statistic in order to detect the location of hotspots and coldspots. For the summary variables (total PTG and total PTSD), two maps were elaborated in order to visualise geographically the spots detected in the city context. Figures 2 and 3 show that both the PTG and PTSD hotspots were located at city's old centre (downtown), while their coldspots were seen in the peri-urban areas.

\section{Discussion}

The non-random distribution of disruptive and healthy responses according to the degree of damage experienced by Cauquenes in the F-27 (which has persisted for 6 years after the event) can be explained by the three theories in mental health of disasters explained in the Introduction of this paper.

\section{First theory}

Even if temporary help is provided, the final level of stress may indeed increase (the resource-conservation model - Hobfoll, 2014) This is precisely what happened to Cauquenes, which received aid that diminished over time after the F-27 earthquake.

\section{Second theory}

The risk of psychological disorders increased the added stres- sors (according to the support deterioration deterrence model Kaniasty and Norris, 2009), such as unemployment and the low income of Cauquenes, which bases its economy on the fruit harvests during the summer (INE, 2015). This kind of increased, longterm post-disaster mental stress due to distribution of disruptive responses such as PTSD and depression, depending on the neighbourhood and their exposure to those events, is borne out by studies of people exposed to a hurricane, e.g., the recent one in New York-USA (Lowe et al., 2016) or migration, such as what was experienced in Lima-Perú (Ruiz-Grosso et al., 2016).

Table 2. Global Moran's I results.

\begin{tabular}{lcccc} 
Variable & Index & Z-score & P-value & Pattern \\
Total PTG & 0.1212 & 3.1211 & $0.0018^{*}$ & Clustered \\
Relating to others & 0.0478 & 1.3189 & 0.1872 & Random \\
\hline Personal strength & 0.0678 & 1.8076 & 0.0707 & Random \\
Spiritual change & 0.1050 & 2.7080 & $0.0068^{*}$ & Clustered \\
\hline New possibilities & 0.1797 & 4.5326 & $0.0000^{*}$ & Clustered \\
Appreciation of life & 0.0856 & 2.2385 & $0.0252^{*}$ & Clustered \\
\hline Total PTSD & 0.1772 & 4.4712 & $0.0000^{*}$ & Clustered \\
PTSD symptoms & 0.1314 & 3.3441 & $0.0008^{*}$ & Clustered \\
\hline PTSD reactions & 0.1698 & 4.2913 & $0.0000^{*}$ & Clustered \\
Suicidal inclination & 0.0274 & 0.8481 & 0.3964 & Random \\
\hline
\end{tabular}

PTG, post-traumatic growth; PTSD, post-traumatic stress disorder. *Statistically significant at the $\mathrm{P}<0.05$ level.

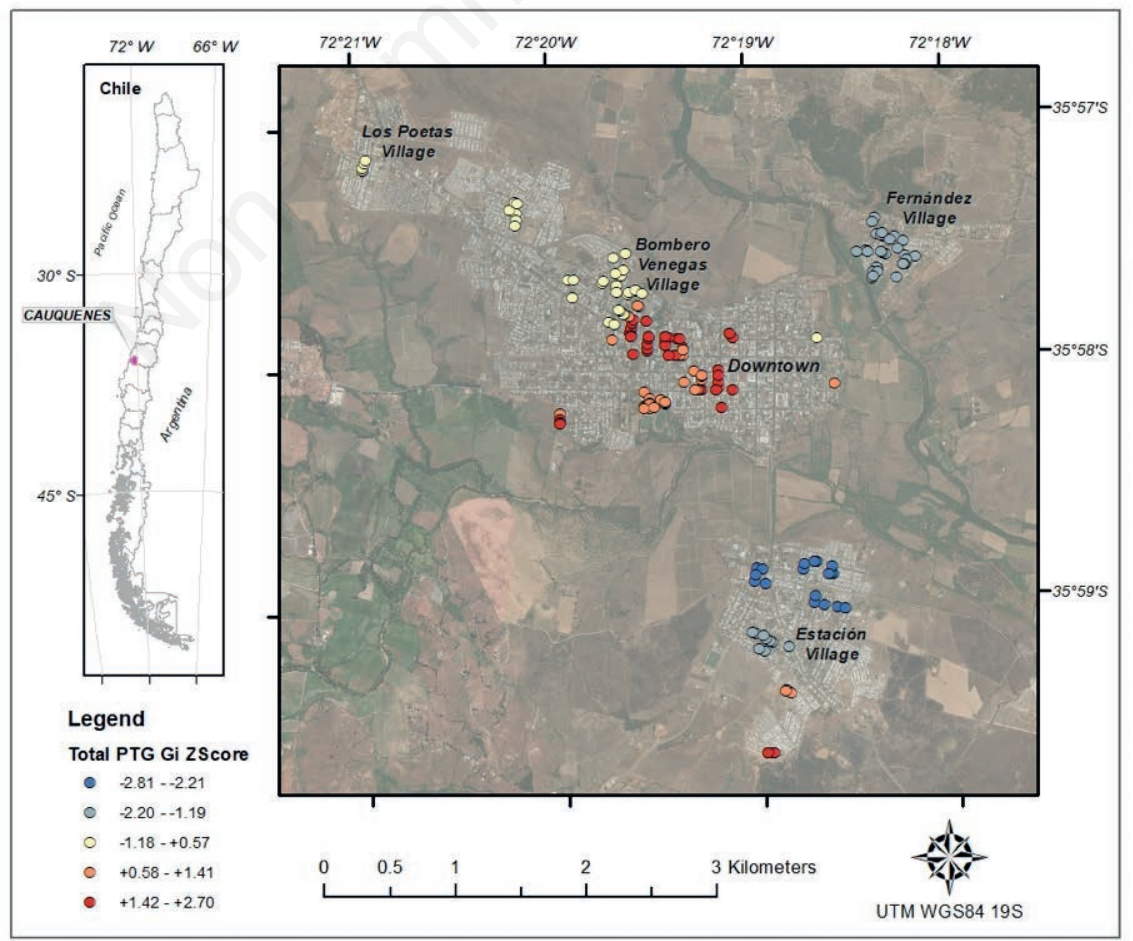

Figure 2. Variation of the total post-traumatic growth (PTG) variable. 


\section{Third theory}

The psychosocial impact model (Leiva-Bianchi et al., 2018b) explains the findings in Cauquenes according to the degree of exposure and the response given as explained in the Introduction. The centre of the city where there the greatest amount of damage was produced by the earthquake, and where people had greatest exposure to disasters (e.g., damaged homes) presented the combined responses of trauma and resilience as proposed by the model.

There are differences within the city. sectors with anti-seismic houses constructed after 1960 were more protected, and the northwestern Los Poetas and Bombero Venegas villages sectors tend to respond with average levels of PTG and low levels of PTSD (Figures 2 and 3). Thus, they were witnesses of the event, which did not affect them directly. Indeed, they did not react with typical disaster-related symptoms and their lives developed normally from a mental point of view.

In contrast, the north-eastern Fernández Village and the southern Estación Village sectors, which were also less exposed to the earthquake, showed a lower level of PTG and average levels of PTSD. They should have been more sensitive to the effects of the earthquake, show a slightly greater disruption and greater resilience. Interestingly, they are socioeconomically opposed sectors with Fernández Village characterised by less income and higher unemployment compared to Estación Village, one of the sectors of the city with the highest income. Despite this, the response was similar. For this reason, it is worth asking how unemployment with emphasis on location affected the psychosocial impact of the disaster. It's important to consider that the combined effect of both stressors is cumulative over time (Lowe et al., 2016). Performing longitudinal studies combined with georeferencing could provide answers this question.

\section{Conclusions}

The results presented here support the potential for developing a GIS-related health care approach in tasks where the impact of cluster evaluation of human health issues can be enabled by map analysis. In this context, it is very important to create geo-databases associated with health care providers at the local, even micro, level, as this would consider variables of health (PTG) and disruption (PTSD) and thus provide a more complete perspective of complex phenomena.

Table 3. Mean value for clustered variables at high and low cluster areas.

\begin{tabular}{lcc} 
Variable & High cluster & Low cluster \\
Total PTG & $73.4 \pm 18.6$ & $64.5 \pm 17.0$ \\
Spiritual change & $8.1 \pm 3.1$ & $6.0 \pm 2.8$ \\
\hline New possibilities & $15.2 \pm 4.8$ & $11.5 \pm 4.3$ \\
Appreciation of life & $10.5 \pm 3.4$ & $8.7 \pm 3.6$ \\
\hline Total PTSD & $19.7 \pm 7.4$ & $6.7 \pm 10.7$ \\
PTSD symptoms & $8.5 \pm 2.6$ & $3.2 \pm 4.2$ \\
\hline PTSD reactions & $11.5 \pm 5.5$ & $3.6 \pm 6.5$ \\
\hline
\end{tabular}

PTG, post-traumatic growth; PTSD, post-traumatic stress disorder.

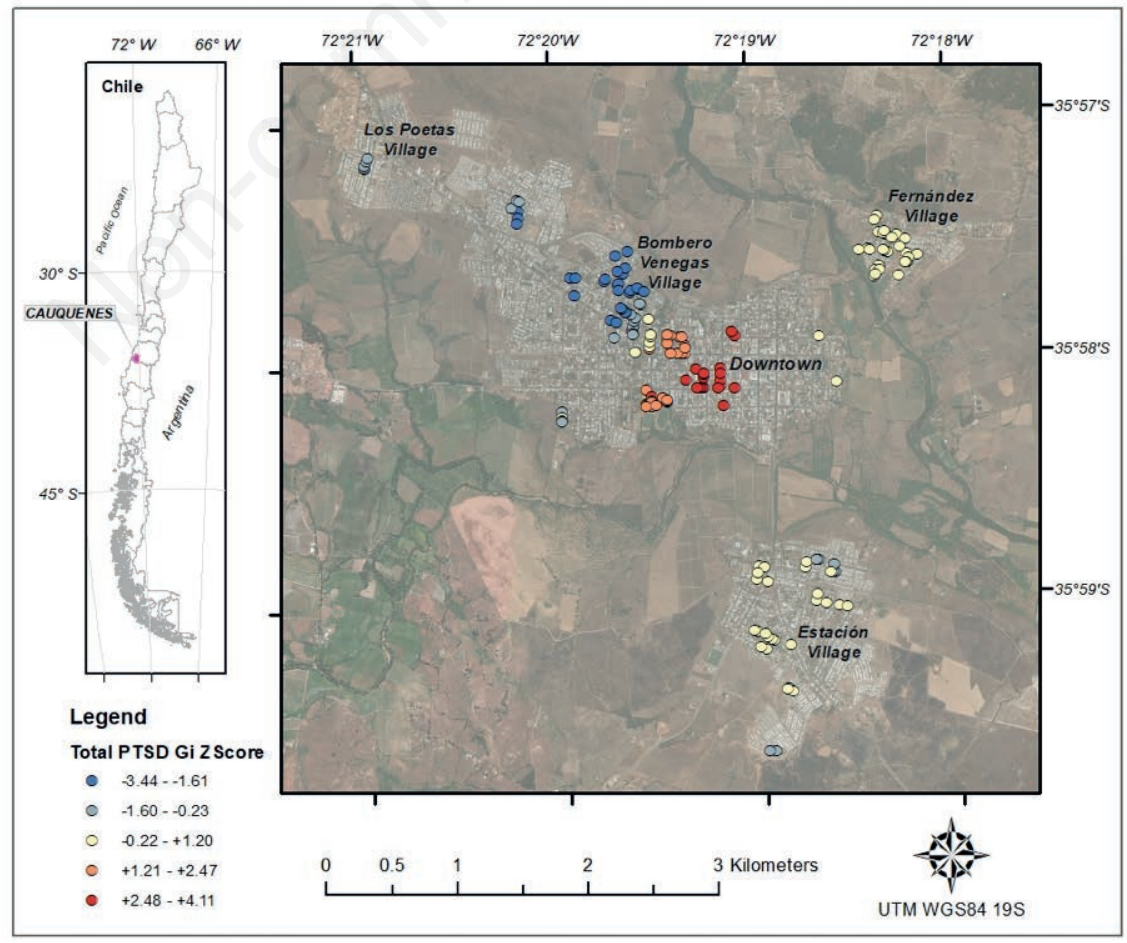

Figure 3. Variation of the total post-traumatic stress disorder (PTSD) variable. 
The spatial identifications found would facilitate exploring the impact of mental health programmes in communities exposed to disasters like earthquakes, thereby improving their quality of life as well as reducing the overall cost.

\section{References}

Abeldaño RA, Fernández R, Estario JC, Enders JE, 2013. Distribución espacial de los trastornos de estrés postraumático en Chile a partir del terremoto del 27-F. Rev Salud Pública 17:40-6.

American Psychiatric Association, 2013. Diagnostic and statistical manual of mental disorders (DSM-5). American Psychiatric Publications, Arlington, USA.

Andrades M, Garcia FE, Calonge I, Martinez-Arias R, 2018. Posttraumatic growth in children and adolescents exposed to the 2010 earthquake in Chile and its relationship with rumination and posttraumatic stress symptoms. J Happiness Stud 19:1505-17.

Bradley R, Greene J, Russ E, Dutra L, Westen D, 2005. A multidimensional meta-analysis of psychotherapy for PTSD. Am J Psychiatry 162:214-27.

Chen YY, Huang XB, Xiao Y, Jiang Y, Shan XW, Zhang J, Cai SX, Liu JB, 2015. Spatial analysis of schistosomiasis in Hubei Province, China: a GIS-based analysis of schistosomiasis from 2009 to 2013. PLoS One 10:e0118362.

Dai W, Chen L, Lai Z, Li Y, Wang J, Liu A, 2016. The incidence of post-traumatic stress disorder among survivors after earthquakes: a systematic review and meta-analysis. BMC Psychiatry 16:188.

Ehring T, Welboren R, Morina N, Wicherts JM, Freitag J, Emmelkamp PMG, 2014. Meta-analysis of psychological treatments for posttraumatic stress disorder in adult survivors of childhood abuse. Clin Psychol Rev 34:645-57.

Fotheringham AS, Brunsdon C, 1999. Local forms of spatial analysis. Geogr Anal 30:340-58.

Getis A, Aldstadt J, 2004. Constructing the spatial weights matrix using a local statistic. Geogr Anal 36:90-104.

Hobfoll S, 2014. Resource caravans and resource caravan passageways: a new paradigm for trauma responding. Intervention 12:21-32.

INE, 2015. Informe empleo provincia Cauquenes. Trimestre JunioAgosto $\mathrm{N}^{\circ}$ 9. Instituto National de Estadísticas, Cauquenes, Chile. Available from: https://regiones.ine.cl/documentos /default-source/region-vii/banco-de-datos-r7/boletines-informativo/empleo/informes-de-empleo/2015/informe-empleojja-15.pdf?sfvrsn=606c6fa9_3

Kaniasty K, Norris FH, 2009. Distinctions that matter: received social support, perceived social support, and social embeddedness after disasters. In: Neria Y, Galea S, Norris F, eds. Mental health and disasters. Cambridge University Press, New York, USA, pp 175-200.

Leiva M, 2010. Creación de un indicador de impacto de terremotos a partir de datos recogidos en personas que vivieron en $27-\mathrm{F}$. Rev Salud Soc 1:178-85.

Leiva-Bianchi M, 2011. Relevancia y prevalencia del estrés posttraumático post-terremoto como problema de salud pública en Constitución, Chile. Rev Salud Pública 13:551-9.

Leiva-Bianchi M, Araneda C, 2015. Confirmatory factor analysis of the post-traumatic growth inventory after Chilean earth- quake. J Loss Trauma 20:297-305.

Leiva-Bianchi M, Cornejo F, Fresno A, Rojas C, Serrano C, 2018a. Effectiveness of cognitive-behavioral therapy for post-disaster distress in post-traumatic stress symptoms after Chilean earthquake and tsunami. Gac Sanit 32:291-6.

Leiva-Bianchi MC, Ahumada F, Araneda A, Botella J, 2018b. What is the psychosocial impact of disasters? A meta-analysis. Issues Ment Health Nurs 39:320-7.

Leiva-Bianchi MC, Gallardo I, 2013. Validation of the short posttraumatic stress disorder rating interview (SPRINT-E) in a sample of people affected by F-27 Chilean earthquake and tsunami. An Psicol 29:328-34.

Lowe SR, Sampson L, Gruebner O, Galea S, 2016. Community unemployment and disaster-related stressors shape risk for posttraumatic stress in the longer-term aftermath of hurricane Sandy. J Trauma Stress 29:440-7.

Mena C, Fuentes E, Ormazábal Y, Palomo I, 2017. Geographic clustering of elderly people with above-norm anthropometric measurements and blood chemistry. Geospat Health 12:523.

Mena C, Fuentes E, Ormazábal Y, Palomo-Vélez G, Palomo I, 2016. Effect of straight-line and road network distances to parks and markets on anthropometric measurements, biochemical markers, and a healthy lifestyle in adult people. Sport Sci Health 12:55-61.

Norris F, Hamblen J, Brown L, Schinka J, 2008. Validation of the short posttraumatic stress disorder rating interview (expanded version, Sprint-E) as a measure of postdisaster distress and treatment need. Am J Disaster Med 3:201-12.

Ord JK, Getis A, 1995. Local spatial autocorrelation statistics: distributional issues and an application. Geogr Anal 27:286-306.

Roger VL, Go AS, Lloyd-Jones DM, Benjamin EJ, Berry JD, Borden WB, Bravata DM, Dai S, Ford ES, Fox CS, 2012. Heart disease and stroke statistics-2012 update: a report from the American Heart Association. Circulation 125:e2-220.

Ruiz-Grosso P, Miranda JJ, Gilman RH, Walker BB, CarrascoEscobar G, Varela-Gaona M, Diez-Canseco F, Huicho L, Checkley W, Bernabe-Ortiz A, CRONICAS Cohort Study Group, 2016. Spatial distribution of individuals with symptoms of depression in a periurban area in Lima: an example from Peru. Ann Epidemiol 26:93-9.

Singh H, Fortington L, Thompson H, Finch C, 2016. An overview of geospatial methods used in unintentional injury epidemiology. Inj Epidemiol 3:32.

Smid GE, Mooren TTM, Van Der Mast RC, Gersons BPR, Kleber RJ, 2009. Delayed posttraumatic stress disorder: systematic review, meta-analysis, and meta-regression analysis of prospective studies. J Clin Psychiatry 70:1572-82.

Tedeschi R, Calhoun L, 1996. The posttraumatic growth inventory: measuring the positive legacy of trauma. J Trauma Stress 9:455-71.

Tedeschi RG, Shakespeare-Finch J, Taku K, Calhoun LG, 2018. Posttraumatic growth: theory, research, and applications. Routledge, London, UK.

$\mathrm{Xu} \mathrm{J,} \mathrm{Liao} \mathrm{Q,} \mathrm{2011.} \mathrm{Prevalence} \mathrm{and} \mathrm{predictors} \mathrm{of} \mathrm{posttraumatic}$ growth among adult survivors one year following 2008 Sichuan earthquake. J Affect Disord 133:274-80.

Zhao F, Cheng S, He G, Huang F, Zhang H, Xu B, Murimwa TC, Cheng J, Hu D, Wang L, 2013. Space-time clustering characteristics of tuberculosis in China, 2005-2011. PLoS One 8:e83605. 